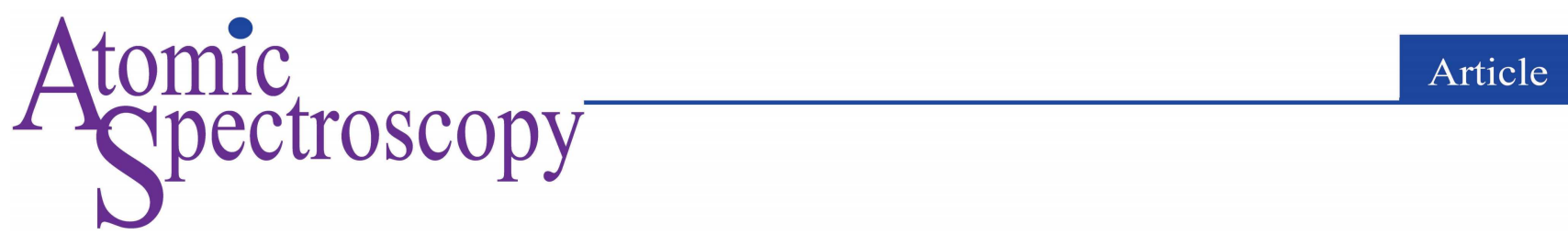

\title{
Fast Quantification and Speciation of Selenium in Dietary Supplements through Handheld XRF and Synchrotron Radiation XAS
}

\author{
Yunyun Li, ${ }^{\mathrm{a}, \#}$ Jiating Zhao, ${ }^{\text {,\# }}$ Lina He, ${ }^{\mathrm{b}}$ Liming Wang, ${ }^{\mathrm{b}}$ Liwei Cui, ${ }^{\mathrm{c}, *}$ Bai Li, ${ }^{\mathrm{b}}$ and Yu-Feng Li ${ }^{\mathrm{b}, *}$

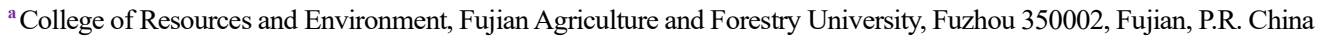

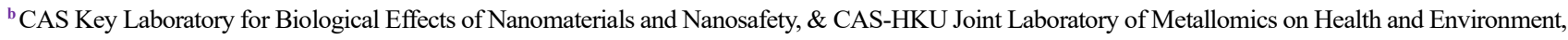 \\ \& Beijing Metallomics Facility, Institute of High Energy Physics, Chinese Academy of Sciences, Beijing 100049, P.R. China \\ ${ }^{\mathrm{c}}$ College of Resources and Environment, University of Chinese Academy of Sciences, Beijing 100049, P.R. China
}

Received: May 18, 2020; Revised: Jun. 08, 2020; Accepted: Jun. 08, 2020; Published: Jun. 25, 2020.

DOI: 10.46770/AS.2020.03.005 \begin{abstract}
we propose the application of a handheld XRF in combination with XAS for the fast quantification and speciation of Se in commercially available dietary supplements. The results of total Se determined by handheld XRF were in good agreement with ICP-MS data, which was also consistent with the labeled value of Se dietary supplements. The XAS analysis of the tested samples showed that Se was mainly present in the form of organic Se. The proposed method is practical and simple for high throughput label verification and quality control of Se dietary supplements. It can, therefore, be a useful method not only for researchers but also for regulators and producers in the analysis of Se dietary supplements.
\end{abstract}

ABSTRACT: The handheld X-ray fluorescence spectrometer (XRF) has the advantages of being easy to carry, simple in operation, non-destructive, and offers fast and relatively accurate detection, while synchrotron radiation X-ray absorption spectroscopy (XAS) has been used for the selenium (Se) speciation of Se-enriched yeast and Se hyperaccumulators. In this study,

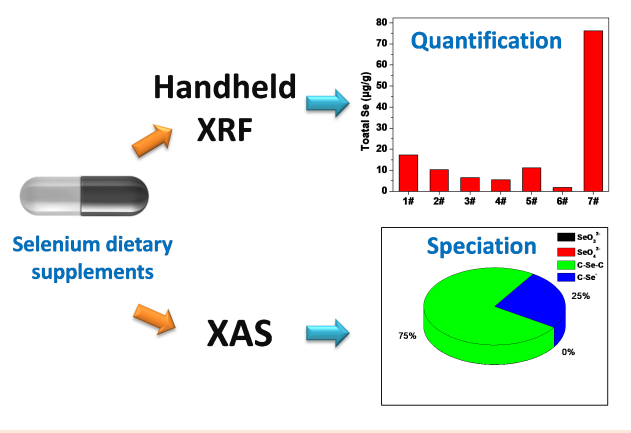

\section{INTRODUCTION}

Selenium (Se) is an essential trace mineral and a component of the selenoproteins, glutathione peroxidases and thioredoxin reductases, some of which play an important role in protecting the organisms from peroxidation damage. ${ }^{1,2}$ Se also plays a vital role in the maintenance of human health, such as for the immune system, antiviral infection, reproduction and thyroid function, etc. ${ }^{3-5}$ Besides, Se protects against the toxicity of heavy metals. For example, it was found that Se-enriched yeast promotes mercury $(\mathrm{Hg})$ excretion and reduces the malondialdehyde level in urine which results from long-term Hg-exposure. ${ }^{6}$ For plants, the application of Se to soil can inhibit the uptake of heavy metals into the tissues from rice, especially in grains. ${ }^{7,8}$ Further, the addition of Se was reported to increase the rice yield and the concentration of other nutritional elements in rice grains grown in $\mathrm{Hg}$ contaminated areas. ${ }^{9,10}$ However, Se can be toxic at high dosage. ${ }^{11}$
The daily intake of less than $0.1 \mathrm{mg} \mathrm{Se} / \mathrm{kg}$ body weight will lead to Se deficiency, while at above $1 \mathrm{mg} \mathrm{Se} / \mathrm{kg}$ body weight it is considered toxic. ${ }^{12}$ Therefore, Se can lead to poisoning of the human body, and result in hair and nail loss, numbness, even paralysis, etc..$^{13,14}$

For individuals diagnosed with Se deficiency, Se dietary supplements are commercially available which are enriched with different forms of Se, either inorganic or organic, or both. Organic $\mathrm{Se}$ is generally less toxic and more bioavailable and is, therefore, considered preferable as a dietary supplement. ${ }^{15}$ However, it has been found that some Se dietary supplements do not contain either the Se dosage or Se species as listed on the label. ${ }^{14}$ Thus, quantification and speciation of Se in dietary supplements must be checked by regulators for label verification and by producers for quality assurance and quality control. The quantification of Se can be achieved using the elemental analysis techniques of inductively 
coupled plasma mass spectrometry (ICP-MS) or atomic fluorescence spectrometry (AFS) after sample pretreatment by acid digestion, which is time-consuming and may cause sample contamination. X-ray fluorescence analysis (XRF) is nondestructive and fast (seconds to minutes) and provides direct analysis with minimal sample pretreatment. ${ }^{16,17}$ The Se levels in dietary supplements fall in the analytical linear range of XRF and are comparable to analytical results by ICP-MS. ${ }^{14}$ Thus, bench-top XRF has been used for fast label verification. Compared to benchtop XRF, handheld XRF is more convenient for quantification, although with higher detection limits. ${ }^{17}$

The speciation of Se is generally achieved by high performance liquid chromatography with ICP-MS (HPLC-ICP-MS) and liquid chromatography coupled to hydride generation-atomic fluorescence spectrometry (LC-HG-AFS), which is considered the "gold standard" method. ${ }^{12,18}$ However, this method is destructive and time-consuming and requires pretreatments, like proteolytic hydrolysis. On the other hand, direct analysis with real time high resolution accurate mass-mass spectrometry (DARTHRAM-MS) has been used to identify non-protein bound selenoamino acids in liquid $\mathrm{Se}$ supplements without chromatography. ${ }^{14}$ However, this method is unsuitable for the analysis of inorganic Se or protein-bound Se in Se supplements, such as in Se-enriched yeasts. Synchrotron radiation-based X-ray absorption spectroscopy (XAS) has been used for the study of the chemical forms of an element and requires minimal sample preparation. For example, direct speciation analysis of Se in Seenriched yeasts was achieved using XAS, the results of which were comparable to HPLC-ICP-MS analysis. ${ }^{19}$ XAS was also applied for the direct analysis of $\mathrm{Se}$ species in Sehyperaccummulator plants. ${ }^{20}$ In this study, XAS is used for the Se speciation in dietary supplements.

The aim of the present study is to offer a fast in situ quantification and speciation method for the analysis of Se dietary supplements by the combined application of handheld XRF and XAS techniques. The proposed method will provide a practical way for high throughput quality control and label verification of Se dietary supplements.

\section{MATERIALS AND METHODS}

Samples preparation. Seven Se dietary supplements were purchased from local or online retailers, which comprises a cross section of the wide range of commercially available samples on the market. The samples were ground into fine powders, then stored at $-20{ }^{\circ} \mathrm{C}$ until analysis. The seven Se supplements were

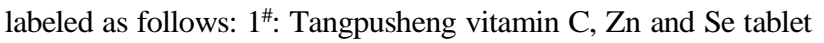
(Wellgen, Luoyang, China), 2*: Shinsb Se and malt schisandra tablets (Shinsb, Zhangqiu, China), 3\#: Xinxibao $\mathrm{Zn}$ and Se chewable tablets (Lvjianyuan, Xinxiang, China), 4\#: Xinxibao Zn and Se chewable tablets (for children) (Lvjianyuan, Xinxiang,
China), 5*: Shinsb Xiweikang Se chewable tablets (Shinsb, Zhangqiu, China), 6": Shinsb Zn and Se tablets (Shinsb, Zhangqiu, China), $7^{\#}$ : Yangshengtang $\mathrm{Zn}$ and Se tablets (Yangshengtang, Haikou, China). All samples were replicated three times.

Quantification of Se by handheld XRF. Total Se was determined using the handheld energy dispersive X-ray fluorescence spectrometer (Explorer 9000, Tianrui, P.R. China) equipped with the component analysis software V1.0 for instrument control and data acquisition. The instrument has a 50 $\mathrm{KV} / 200 \mu \mathrm{A}$ silver target and a window integrated miniature X-ray tube and high-voltage power supply. The XRF instrumental parameters for data acquisition are listed in Table 1. For Se quantification in dietary supplements, reference material (SELM1 yeast, Canada) was used for instrumental calibration. Each sample was measured three times.

Determination of total Se by ICP-MS. A triplicate of sample powder was weighed (approximately $50 \mathrm{mg}$ ) into 15 -mL digestion tubes and mixed with $5 \mathrm{~mL} \mathrm{HNO}_{3}(\mathrm{BV}-\mathrm{III})$ and $0.5 \mathrm{~mL} \mathrm{H}_{2} \mathrm{O}_{2}$ (MOS). The mixtures were kept at room temperature overnight for pre-digestion. The samples were digested at $120^{\circ} \mathrm{C}$ for 6 hours, then the mixtures evaporated to approximately $1 \mathrm{~mL}$ at $90{ }^{\circ} \mathrm{C}$. The residual solution was diluted to $4 \mathrm{~mL}$ with $2 \% \mathrm{HNO}_{3}$ for total Se analysis. Total Se was determined using the Thermo X7 ICP-MS (Thermo Electron Corp., USA) in the collision cell mode. The calibration standard solution of Se was obtained by diluting the Se standard stock solution (1000 mg/L, Quality Control Standard 21, Spex. CLMS-1, USA) with $2 \%$ (v/v) $\mathrm{HNO}_{3}$. The reference material (SELM-1 Yeast, Canada) was digested, evaporated and diluted with samples for quality assurance/control purposes. The certified Se content was $2059.2 \pm 64.3 \mu \mathrm{g} / \mathrm{g}$. The recovery of Se in the reference material was $85.1 \%$.

Speciation of Se with XAS. The speciation of Se in the dietary supplements was performed by following our previous method using XAS. ${ }^{19}$ Briefly, the Se K-edge X-ray absorption spectra of the sample powders were collected at beamline $14 \mathrm{~W}(3.5 \mathrm{GeV}$, $250 \mathrm{~mA}$ ), Shanghai Synchrotron Radiation Facility (SSRF, P.R. China). The beamline $14 \mathrm{~W}$ was equipped with a Si (111) doublecrystal monochromator that was detuned to minimize the harmonic content of the beam. The sample powders were pressed into 1-mm thick slices and spread onto scotch tapes. The absorption spectrum was set as pre-edge $30 \mathrm{eV}$ and after-edge 100 $\mathrm{eV}$. The XAS of the samples was recorded at room temperature in compounds of selenite $\left(\mathrm{SeO}_{3}{ }^{2-}\right)$, selenate $\left(\mathrm{SeO}_{4}{ }^{2-}\right)$,

Table 1 The Instrumental Conditions of Handheld XRF

\begin{tabular}{lc}
\hline Parameter & Value \\
\hline Votage $(\mathbf{k V})$ & $5-50$ \\
Detector time (s) & 60 \\
Carrier gas & Air \\
Pipe pressure $(\mathrm{kV})$ & $5-50$ \\
Pipe flow $(\boldsymbol{\mu A})$ & $5-200$ \\
\hline
\end{tabular}


Table 2. Total Se Determined by Handheld XRF and ICP-MS ( $\left.\mu \mathrm{g} \mathrm{g}^{-1}, \mathrm{n}=3\right)$

\begin{tabular}{lcccc}
\hline Samples & Name of supplements & Handheld XRF & ICP-MS & Labeled total Se \\
\hline 1\# & Tangpusheng vitamin C, Zn and Se tablets & $17.32 \pm 0.48$ & $17.56 \pm 1.92$ & 17.44 \\
2\# & Shinsb Se and malt schisandra tablet & $10.30 \pm 0.10$ & $13.07 \pm 0.77$ & 13 \\
3\# & Xinxibao Zn and Se chewable tablets & $6.51 \pm 0.07$ & $5.51 \pm 0.50$ & 6.7 \\
4\# & Xinxibao Zn and Se chewable tablet (for children) & $5.45 \pm 0.06$ & $4.44 \pm 0.25$ & 5.6 \\
$\mathbf{5 \#}$ & Shinsb Xiweikang Sechewable tablets & $11.14 \pm 0.10$ & $12.82 \pm 1.00$ & 11 \\
6\# & Shinsb Zn and Se tablets & $1.87 \pm 0.03$ & $1.27 \pm 0.02$ & $1-2$ \\
7\# & Yangshengtang Zn and Se tablets & $76.30 \pm 0.50$ & $84.93 \pm 4.53$ & 76.92 \\
\hline
\end{tabular}

methylselenocysteine (MSeCys, C-Se-C), and selenocysteine (SeCys, C-Se'), and were recorded at room temperature in transmission mode. After background subtraction and normalization, the data for the samples were fit to all model compounds using the Athena and IFEFFIT program. Due to beam time limitation, only samples $2^{\#}$ and $5^{\#}$ were used for Se speciation.

\section{RESULTS AND DISCUSSION}

Total Se in dietary supplements. The total Se of the seven Se dietary supplements was determined in triplicate with both handheld XRF and ICP-MS. The results are listed in Table 2. It can be seen that the handheld XRF and ICP-MS data show good agreement and are also consistent with the labeled values. Furthermore, there is a positive correlation between the handheld XRF and ICP-MS data $\left(r^{2}=0.998\right)$. These results show that handheld XRF is a non-destructive and reliable tool to analyze the Se contents in dietary supplements. Handheld XRF has been widely used for determining the elemental composition in different samples, including soils, sediments and rocks. ${ }^{16}$ The traditional technique for label verification in Se dietary supplements on the markets is ICP-MS and HPLC-ICP-MS. Samples digestion was needed in the ICP-MS and it takes at a minimum 2 3 h per sample. Sample pretreatment is unnecessary and each sample was analyzed in triplicate in under $1 \mathrm{~min}$ in determining total Se using handheld XRF. Moreover, the handheld $\mathrm{XRF}$ is easy to carry and has no requirements for the experimental site, so total Se can measure any time and any place. In this study, handheld XRF was found to be suitable for the fast in situ quantification of Se in dietary supplements with minimum sample pretreatment, and can be used for high throughput screening at a much shorter analysis time from approximately 5 hours (ICP-MS) to less than 1 minute (handheld XRF).

Speciation of Se in Se supplements. Se speciation in different Se supplements $\left(2^{\#}\right.$ and $\left.5^{\#}\right)$ was performed by XAS. The results of linear combination of the Se K-edge XAS spectra are shown in Fig. 1 and Table 3. In samples $2^{\#}$ and $5^{\#}$, Se was mainly in the form of organic Se, using selenocysteine (SeCys, C-Se-) and methylselenocysteine (MSeCys, $\mathrm{C}-\mathrm{Se}-\mathrm{C}$ ) as reference compounds. As mentioned earlier, for the speciation of Se, HPLC-ICP-MS is considered the gold standard method. However, our previous study confirmed that the quantification of Se species in Se-
Table 3. The Numerical Results of Least Squares Fit for the Spectra of Se in Dietary Supplements to that of the Standard Se-containing Compounds $\quad \mathrm{SeO}_{3}{ }^{2-} \quad$ (Selenite), $\mathrm{SeO}_{4}{ }^{2-} \quad$ (Selenate), C-Se-C (Methylselenocysteine), C-Se' (Selenocysteine, SeCys))

\begin{tabular}{lccccc}
\hline Samples & $\begin{array}{c}\mathrm{SeO}_{4}{ }^{2-} \\
(\boldsymbol{\%})\end{array}$ & $\begin{array}{c}\mathrm{SeO}_{3}{ }^{2-} \\
(\boldsymbol{\%})\end{array}$ & $\begin{array}{c}\mathrm{C}^{2} \mathbf{S e}^{-} \\
(\boldsymbol{\%})\end{array}$ & $\begin{array}{c}\mathrm{C}-\mathrm{Se}-\mathrm{C} \\
(\boldsymbol{\%})\end{array}$ & $\begin{array}{c}\mathrm{R}- \\
\text { factor }\end{array}$ \\
\hline $\mathbf{2 \#}$ & $\mathrm{ND}^{*}$ & $\mathrm{ND}^{*}$ & $75 \pm 5$ & $25 \pm 5$ & 0.001 \\
$\mathbf{5} \#$ & $\mathrm{ND}^{*}$ & $\mathrm{ND}^{*}$ & $76 \pm 4$ & $23 \pm 4$ & 0.002 \\
\hline
\end{tabular}

*ND: Not detected.

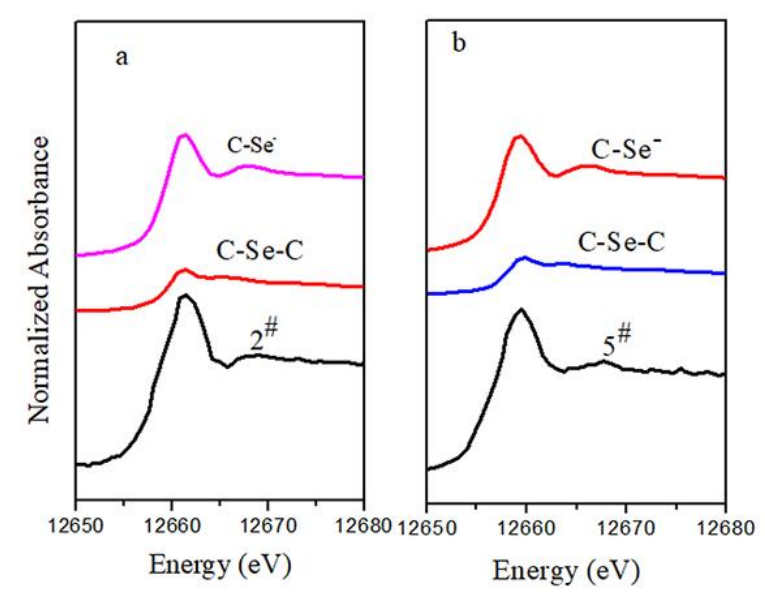

Fig. 1 Linear combination analysis of Se K-edge XAS spectra of selenium dietary supplements to the model Se compounds. In reference to those Se species found in the samples, the standards spectra are shown as follows: $\mathrm{C}-\mathrm{Se}^{-}$(selenocystine) and $\mathrm{C}-\mathrm{Se}-\mathrm{C}$ (methylselenocystine). a, b represents 2\# and 5\#, respectively.

enriched yeast by XAS also agrees well with the results obtained by HPLC-ICP-MS. ${ }^{19}$ Therefore, XAS can be considered a reliable method for the quantification of Se species in Se dietary supplements. The Se species in dietary supplements includes inorganic Se, such as selenite, selenate, selenide and elemental Se and organic Se in which Se is covalently bound with $\mathrm{C}$ and other atoms, such as SeCys (C-Se-), and MeSeCys (C-Se-C), etc. Organic Se is less toxic and more bioavailable. ${ }^{21}$ Therefore, from a human nutrition perspective, supplements containing organic Se are preferable. ${ }^{21}$ Although the Se species were not listed on the manufacturer's label, our study found that Se in the $2^{\#}$ and $5^{\#}$ samples were mainly organic Se. In addition, our study was able to obtain quantitative information about the different organic Se forms for both the $2^{\#}$ and $5^{\#}$ samples, where about $75 \%$ of the total 
Se was in the form of C-Se using SeCys as the model compound, while about $25 \%$ of Se was in the form of C-Se-C using MeSeCys as the model compound.

For Se speciation, $1 \mathrm{~h}$ for sample pretreatment and a minimum of $30 \mathrm{~min}$ of analysis time per sample were needed using HPLCICP-MS or LC-HC-AFS. Moreover, Se species might be transformed during sample pretreatment. When XAS was applied to speciation analysis, analysis time was reduced from nearly $2 \mathrm{~h}$ to $40 \mathrm{~min}$. This technique has no requirement for packaging of $\mathrm{Se}$ supplements. The synchrotron radiation-based techniques have become more widely used. ${ }^{22}$ However, the lack of beamtime hinders the wider application of synchrotron radiation-based techniques, such as XAS as used in the present study for routine screening of Se supplements. Fortunately, laboratory scale XAS is emerging. ${ }^{23}$ Therefore, Se speciation in dietary supplements may in the near future also be achieved with laboratory scale bench-top XAS

\section{CONCLUSIONS}

A fast quantification and speciation of $\mathrm{Se}$ in commercially available dietary supplements was achieved by using the combination of a handheld XRF with XAS technique. Total Se analysis by handheld XRF showed good agreement with ICP-MS results, which is also consistent with the labeled value. In addition, the XAS analysis of the selected samples proved that Se is mainly present in the form of organic Se. It can, therefore, be stated that the combination of handheld XRF with XAS provides high throughput quality control of Se dietary supplements.

\section{AUTHOR INFORMATION}

\section{Corresponding Author}

* L. W. Cui

Email address: cuiliwei@ucas.ac.cn

*Y. -F. Li

Email address: liyf@ihep.ac.cn

\section{Notes}

\# These authors contribute equally to this work. The authors declare no competing financial interest.

\section{ACKNOWLEDGMENTS}

This work was financially supported by the National Natural Science Foundation of China (Grant Nos. 11975247, 41807450), the Ministry of Science and Technology of China (2016YFA0201600), and the Guizhou Department of Science and Technology, P. R. China (No. 498 QKH-2016-2804).We thank the staffs at BL14W (SSRF) for their assistance during measurement and data processing.

\section{REFERENCES}

1. O. H. Al-Taie, J. Seufert, S. Karvar, C. Adolph, H. MörK, M. Scheurlen, J. Kohrle and F. Jakob, Nut. Cancer, 2003, 46, 125-130.

2. B. M. Lacey, B. E. Eckenroth, S. Flemer Jr. and R. J. Hondal, Biochemistry, 2008, 47, 12810-12821.

3. M. P. Rayman, Lancet, 2000, 356, 233-241.

4. F. P. Bellinger, A. V. Raman, M. A. Reeves and M. J. Berry, Biochem. J., 2009, 422, 11-22.

5. P. Chariot and O. Bignani, Muscle. Nerve, 2003, 27, 662-668.

6. Y.-F. Li, Z. Dong, C. Chen, B. Li, Y. Gao, L. Qu, T. Wang, Y. Zhao and Z. Chai, Environ. Sci. Technol., 2012, 46, 11313-11318.

7. L. Lin, W. Zhou, H. Dai, F. Cao, G. Zhang and F. Wu, J. Hazard. Mater., 2012, 235, 343-351.

8. J. T. Zhao, Y.-F. Li, Y. Y. Li, Y. X. Gao, B. Li, Y. Hu, Y. L. Zhao and Z. F. Chai, Metallomics, 2014, 6, 1951-1957.

9. Y.-F. Li, J. T. Zhao, Y. Y. Li, H. J. Li, J. Zhang, B. Li, Y. X. Gao, C. Y. Chen, M. Luo and R. Huang, Plant Soil, 2015, 391, 195-205.

10. Y. Y. Li, W. J. Hu, J. T. Zhao, Q. Chen, W. Wang, B. Li and Y.-F. Li, Ecotoxicol. Environ. Safe., 2019, 182, 109447.

11. S. J. Fairweather-Tait, Y. Bao, M. R. Broadley, R. Collings, J. E. Hesketh and R. Hurst, Antioxid. Redox. Signal., 2011, 14, 1337-1383.

12. C. B'hymer and J. J. Caruso, J. Chromatogr. A., 2006, 1114, 1-20.

13. M. Vinceti, E. T. Wei, C. Malagoli, M. Bergomi and G. Vivoli, Rev. Environ. Health, 2001, 16, 233-252.

14. T. Hanley, K. Kubachka, A. Taylor and S. Kern, J. Anal. At. Spectrom., 2017, 32, 1196-1202.

15. C. Thiry, A. Ruttens, L. De Temmerman, Y. J. Schneider and L. Pussemier, Food Chem., 2012, 130, 767-784.

16. K. E. Young, C. A. Evans, K. V. Hodges, J. E. Bleacher and T. G. Graff, Appl. Geochem., 2016, 72, 77-87.

17. K. G. Mejía-Piña, M. A. Huerta-Diaz and O. González-Yajimovich, Talanta, 2016, 161, 359-367.

18. H. Yang and M. He, Clean-Soil Air Water, 2016, 4, 1538-1546.

19. Y.-F. Li, X. Wang, L. Wang, B. Li, Y. Gao and C. Chen, J. Anal. At. Spectrom., 2010, 25, 426-430.

20. L. Cui, J. Zhao, J. Chen, W. Zhang, Y. Gao, B. Li and Y.-F. Li, Plant Soil, 2018, 425, 577-588.

21. M. Navarro-Alarcon and C. Cabrera-Vique, Sci. Total. Environ., 2008, 400, 115-141.

22. H. Hu, J. Zhao, L. Wang, L. Shang, L. Cui, Y. Gao, B. Li and Y.-F. Li, TRAC-Trend. Anal. Chem., 2019, 112, 115721.

23. R. Bès, T. Ahopelto, A. P. Honkanen, S. Huotari, G. Leinders, J. Pakarinen and K. Kvashnina, J. Nucl. Mater., 2018, 507, 50-53. 